\title{
An in Depth Comparative Analysis of Software Tools for Modelling and Simulating Business Processes
}

\author{
Rallis C. Papademetriou ${ }^{1}$ and Dimitrios A. Karras ${ }^{2}$ \\ ${ }^{1}$ Faculty of Technology, University of Portsmouth, Anglesea Road, Portsmouth, PO1 3DJ, U.K. \\ ${ }^{2}$ Automation Department, Serea Hellas Institute of Technology, P.C. 34400 Psachna, Evoia, Greece \\ rallis.papademetriou@port.ac.uk,dakarras@teiste.gr
}

Keywords: Business Process, Modelling Requirements, Comparative Analysis, Business Process Modelling Tools.

Abstract: Undoubtedly, Business process modelling is an increasingly popular research area for both organisations and enterprises due to its usefulness in facilitating better planning of resources, business reengineering and optimized business performance. The understanding of Business Process is an essential approach for an Organization to achieve set objectives and improve its operations. Business Process Modelling is a representation of the processes of the Organization. Several modelling techniques have been proposed and used to capture the characteristics of business processes. However, available techniques view business processes from different perspectives and have different features and capabilities. Furthermore, to date limited guidelines exist for selecting appropriate modelling techniques based on the characteristics of the problem and its requirements. Recent development has shown the importance of representing processes to carry out continuous improvement. The modelling and simulation of Business Processes has been able to show Business Analysts, and Managers where bottleneck exists in the system, how to optimize the Business Process to reduce cost of running the Organization, and the required resources needed for an Organization. This paper presents a comparative analysis of some popular business process modelling techniques. The comparative framework is based on the following major criteria: data flow capability, logical reasoning and understandability, specification of roles, and capability of simulation, flexibility and ease of use, simulation support and scope. The proposed framework can serve as the basis for evaluating further modelling techniques and generating selection procedures focusing on a comparison of existing tools to implement these techniques. This is to enable a potential user/modeller choose the right technique and tool in modelling critical Business Processes in order to analyse and optimize the operations of an Organization.

\section{INTRODUCTION}

Process is basically a part of everyday life. Process is involved in all actions carried out by both humans and organisation to achieve an objective. In organisations, value-added activities are becoming the central focus in the achievement of objectives set by an organisation. These value-added activities are referred to as Business process. Experts in Business analysis and Information System Analysis have both drawn the conclusion that the success of a system starts with a clear understanding and knowledge of the Business process of the organisation (AguilarSaven, 2003). The Business Process Model provides a platform for the analysis of the processes to be carried out. Business Process Modelling is a method commonly used in organizations to increase awareness of the business process, and to simplify the complexity of the organization by disaggregating the process (Recker et al., 2009). The principles of Business Process Model can be traced back to the idea of Division of Labour in manufacturing by Adam Smith in 1776. According to Adam Smith, the breaking down of the process into specialised tasks, and the tasks assigned to different people in the chain of activities, would simplify and speed up the process. Although process modelling principles have been in existence since the 18th century, and the term Business Process Modelling was first used in the 1960s in an article, it only became popular in 1990s with the prevalence of Information Technology.

On its own, Business Process Modelling is not an improvement tool; it is simply a means to an end. It outlines the activities carried out in the organisation, providing a framework for improvement to be carried out. Business Process Modelling techniques are used 
to design of the process model; and are implemented using software tools.

With the rapid growth and embrace in IT from the 1990 s to this present time, BPM has gained more popularity in organisations. This has led to the growing number of Business Process Modelling tools, techniques, and methodologies. These different techniques of Business Process Modelling have their distinct uses and purposes. Due to the lack of guide, and a numerous presence of approaches, selection of the right tool and techniques has become more complex for organisations.

In view of this, a critical comparative analysis of the Business Process Modelling techniques and tools are carried out in this paper. This is to enable organizations to understand the right techniques and tools to use, as well as the pitfall of these techniques. Modelling of a Business process is used in detecting constraints of a system and providing a framework for carrying out continuous improvement of an Organization. This study aims at providing background knowledge of Business Process Management as an essential unit in carrying out continuous improvement, with focus on the Business Process Modelling Techniques and especially on the requirements and selection of proper software tools. Moreover, it seeks to determine and compare the modern mathematical and Information Systems based techniques and tools of Business Process modelling.

\section{BUSINESS PROCESS MODELS COMPARATIVE ANALYSIS}

A business model is a framework used to represent the complex reality of an organization. The business model is used to present a clear description of the objectives, strategies, organizational structure, and operations of an Organization. Business Models such as the Organizational Chart, and financial statements have been used by organizations for decades. In recent times, business models such as the Business Organizational Model, Business Rule Model, Business Motivational Models, and Business Process Model have been introduced (Bridgeland and Zahavi, 2009). These newer models do not displace the previous models, but to focus on other parts of the complex reality of a business.

The model of a business system can be classified into two categories (Kalnins et al.,):

i. As-is Model: This is a representation of the present state of the Business System which includes the Organizational Structure, the main operations of the organization, the logical behaviour aspects of the system - who carries out a task, when it is to be carried out, and what it aims to achieved.

ii. To-be Model: This is an improvement of the Asis Model after an analysis of the present state has been carried out. It is a representation of what the system can be and how the operations can be optimised.

A branch of Business Model which is considered to be an essential aspect of Business Process Management is the Business Process Model.

Process Model is used to represent a step-by-step approach in operations of an Organization. The Business Process model is a means to an end; showing what the series of activities aim to achieve, who/what department is to carry out the activities, and what stage the activity is to be carried out in the organizational operations process. The representation of the interactions between the tasks, operations, and processes provides a foundation for the improvement of the efficiency, effectiveness and business process of an organization (Business Process Modelling, 2007).

In present times, the research on Business Process Modelling is beginning to gain attention in both the academic and industrial environment. It is not just restricted to Business Process Management; it can be applicable to areas such as web development analysis, software development / engineering, and serviceoriented structure (Prezel et al.,). Business Process Modelling is not only used in conventional business environment, but also in government agencies, charity organizations, and all process-oriented systems. A Business Process Model can be used repeatedly for similar processes (Yamamoto et al., 2005). The increasing awareness and embrace of Information Technology/Information Systems has heightened the demand for process improvement with the aid of Business Process Modelling. The top priority of modelling a Business Process is to improve the system's performance through the optimisation of the activities carried out to achieve set objectives. Figure 1 illustrates the representation of the present activities of a system (AS-IS), and what the process is to become (TO-BE) order to optimize production/services. Other purposes to model a Business Process includes; communication, training, process reuse, persuasion in sales (Bridgeland and Zahavi, 2009).

The increase in demand of process modelling has equally made it as relevant as existing process optimization tool such as Total Quality Management (TQM). To model a Business Process, different 
techniques can be used. These techniques have been developed for different purposes and are more suitable in various aspects. Business Process Modelling techniques are concerned with the mapping and workflow of activities in a system in order to be able to carry out analysis, and also provide a framework for change management (Business Process Modelling, 2013).

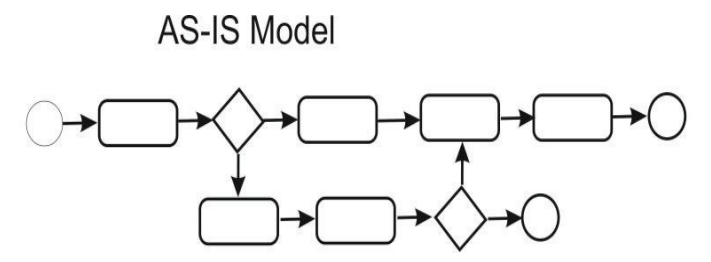

TO-BE Model

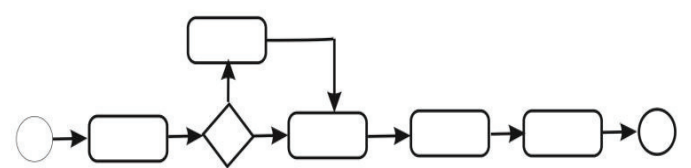

Figure 1: Example of an AS-IS and TO-BE Business Process Model.

The techniques of Business Process Modelling can be classified into three different set based on their representation of a model (Vergidis et al., 2008):

- Diagrammatic Model: At the inception of Business Process Model, these techniques were being solely used. It is a simple and easy-tocommunicate graphical representation, originally developed for software analysis and development. Initially, the representation of these techniques was plain graphics.

- Mathematical Model: These are referred to as second generation of BPM techniques. These techniques are well defined and precise, and can be analysed mathematically to extract knowledge. Though these models are very appropriate in carrying out quantitative analysis and improvement of a process, they are not suitable in modelling complex constructs based on no emphasis on the diagrammatical representation of the process such as decision points. Representation of a Business process mathematically may prove to be much more complex than diagrammatic representation.

- Business Process Languages: The most recent set of BPM techniques to be developed. The development of these set of techniques, like the first generation set, was influenced by software development. Business process languages is an Information Technology based technique in used to represent Business Processes. This latest trend of BPM techniques is dynamic in nature and rapidly evolving.

This section provides a comparative analysis of modern Business Process Modelling techniques. In this chapter, a basis for comparing the techniques is developed; the techniques are reviewed, stating their strengths and weakness (if any). The chapter ends with recent methodologies used in modelling an Enterprise.

In the study carried out, ten techniques were selected. This selection was based on popularity on websites of reputable Business Process Management software developers, and few existing recent journals from publishers such as IEEE, Science Direct.

In carrying out the comparative study of Business Process Model techniques, the answers to the following questions provided guidelines on how to achieve the objective:

- What are the bases for comparing the different Business Process Modelling techniques?

- What are the strengths and weakness in using the technique?

- What are the basic focuses of the techniques?

Past researchers have classified and compared the BPM techniques based on different views; in her article, Aguilar-Saven (2003) classified the techniques based on the purpose of the model and model change permissiveness (active and passive).

Another classification based on the representation of the techniques; Mathematical, Diagrammatical, and BP language (Vergidis et al., 2008).

However, most of these techniques make use of the conventional approach, representing Business Process (regardless of the form) as series of activities, emphasizing the structure of the flow of activities, and the resultant output from the activities; and also, used for similar purpose.

Hence, an approach for comparison is proposed based on the different techniques in this project to not only aid Academicians, but also aid BPM practitioners in selecting a technique.

In answering the research questions, four features were proposed; and the strengths and the weakness were stated. The features were based on intensive study of the general characteristics of Business Process Modelling techniques, and purpose of model classification by Aguilar-Saven (2003): learning description; decision support for process design, control, and execution; Information Technology enactment support. 
The Table 1 below outlines and describes the features that were used in the comparison.

Table 1: Business Process Comparison Criteria.

\begin{tabular}{|c|c|}
\hline Features & Description \\
\hline $\begin{array}{l}\text { Data Flow } \\
\text { Approach }\end{array}$ & $\begin{array}{l}\text { All techniques outline the flow of activities } \\
\text { in the model; data flow description further } \\
\text { explains what information is passed along. In } \\
\text { some modelling techniques, text is combined } \\
\text { with the visual representation of activities in } \\
\text { the process flow. This approach is perhaps } \\
\text { regarded as the most important form in the } \\
\text { communication of process models to } \\
\text { stakeholders. This feature explains the } \\
\text { additional description offered by the } \\
\text { techniques }\end{array}$ \\
\hline $\begin{array}{c}\text { Logical } \\
\text { Approach }\end{array}$ & $\begin{array}{l}\text { In this context, logical reasoning is the } \\
\text { process of using statements/notations/ } \\
\text { arguments in describing conditions which } \\
\text { must be met for an activity to be carried out. } \\
\text { This feature adds more structure in the } \\
\text { process model, providing alternate routes in } \\
\text { achieving the objectives of the process. This } \\
\text { feature is highly relevant in making decisions } \\
\text { in the Organization }\end{array}$ \\
\hline $\begin{array}{c}\text { Role } \\
\text { Approach }\end{array}$ & $\begin{array}{l}\text { In process modelling techniques, this feature } \\
\text { is usually a secondary structure included. The } \\
\text { use of roles in techniques gives a clear } \\
\text { description of who is responsible for the } \\
\text { different tasks in the process, providing } \\
\text { organization distribution of activities. The } \\
\text { role assignment feature targets analysis of } \\
\text { administrative procedures, providing a } \\
\text { guideline in carrying out structural change in } \\
\text { Organizations }\end{array}$ \\
\hline Simulation & $\begin{array}{l}\text { Simulation is the act of imitating the } \\
\text { behaviour or operations of real-world } \\
\text { Business Process or systems. This feature is } \\
\text { used to carry out virtual analysis of a process }\end{array}$ \\
\hline
\end{tabular}

\section{BUSINESS PROCESS MODELLING SOFTWARE TOOLS REQUIREMENTS AND COMPARATIVE ANALYSIS}

Business Process Modelling/ Management software is the platform used in the implementation of the techniques discussed.

From researches on existing Business Process Modelling software available, BPM software are developed based on two distinct key functions:

1. Modelling of a Business Process.

2. Simulation of Business Process Model.
i. Analysis
ii. Optimization

Based on researches carried out in this work, it has been observed that some BPM software tools are just restricted to the design of the model, while some others have the capabilities of both functions. Some of the software applications have more than one technique embedded in them. In designing the Business Process Model, a modeller chooses the technique provided by the available software. For example, ARIS architecture discussed previously provides its own software which uses BPMN and EPC in the design of a Business Process Model. With the simulation function of the software, the results of the operations can be determined without necessarily spending huge capital of running the actual process in real-world. There are certain essential features which a Business Process Model should have:

- Complete Information: The resources, organizational units, idle time and operating time and everything related to the process should be stated.

- Realistic \& Executable: The AS-IS model should be a real representation of the process, and also the TO-BE model should be achievable.

- Ability to be Partitioned: This is to enable analysis of a process unit to be carried out.

- Traceability: No activity should be without a connection to the start event.

Simulation mimics the actual process of a system. In Business Process context, simulation goes beyond imitating the system; simulation of a Business Process Model is carried out to achieve this given objectives in the Organization:

> Process and resource analysis and optimization

> Identification of Bottleneck

> Human resources planning

> Risk assessment and risk minimization.

The consideration whether Simulation of the Business Process is important in the organization is dependent of; the effort in preparing the process model and the aims to be achieved from simulation. The output of the simulation is a result of the model designed.

In carrying out the simulation, the following pieces of information are first determined:

- Processing time per function/ activity

- Number of available resources / equipments

- Work time for each of the resources / equipments

- Additional information in getting a precise result. E.g. interruptions due to pause in activities, parts replacement in the cause of the process.

The more detailed the information gathered, the more precise the simulation output. 
In the search for Business Process software, at least fifty software applications were discovered. A question posed by Organization is "What is the best modelling software to choose?"

Based on researches carried out, below are different characteristics which are to be considered in choosing a business process modelling software:

- Notation and Technique

- Cost

- Operating System Capability

- Functionality

- Documentation format

Discussed below is a brief summary of some BPM software. The software discussed here is a mixture of both freeware and commercial version, therefore not all were tested. For this reason, some pieces of the information here are retrieved from the BPM software companies and third-party vendors:

1. ADONIS: This software was created and first released in 1995 by BOC Information Technologies Consulting, supporting Business Process Management based on a framework BPMS which was developed at the University of Vienna. This software is free but a closed source which makes use of BPMN tool and with the commercial version providing simulation function. ADONIS software is created in an easyto-use style so a beginner can easily understand how to use.

2. Enterprise Architect Suite: This software was developed by Sparx Systems based on UML. The Enterprise Architect was initially released in 2000 and supported just UML, but subsequent releases has seen it supporting basically all ObjectOriented technique - UML,BPMN, BPEL, SPEM. Aspects covered by this software not only include Business Process Modelling design, but also Simulation, Development Lifecycle, requirements management, project management. The software is a complete BPM suite which can be useful for software developers, modellers, Business Analyst, and other Organization entities.

3. Microsoft Visio 2013: The Microsoft Visio is more of a diagramming application which supports the design of a Business Process Model. This application first developed in 1992 by Shapeware Corporation, the product was later acquired by Microsoft. Microsoft Visio is not particularly based on a particular notation or technique. It provides different notation and techniques like IDEF0, BPMN2.0, UML; its own flowchart technique - Microsoft SharePoint workflow; and different software and database diagrams. Using the Microsoft Visio, a modeller can decide to also design his notations.

4. BIZAGI BPM Suite: Bizagi BPM Suite was developed by Bizagi Ltd., a privately owned company founded in 1989. Bizagi BPM Suite consists of three tools - Process modeller, Studio, and Server. The Business Process are drawn and documented in the Process Modeller; the process applications are built in the studio and stored in a database, the execution and control of the built Process application takes place in the server. This all-in-one suite provides a graphical real- time tracking, simulation and monitoring of the process, providing Business Process management to companies such as Schlumberger, Adidas Group, Audi, and Petrobas. Bizagi supports BPMN, and also compatible with XML Definition Process Language (XPDL).

5. Enterprise Dynamics: The Enterprise dynamics software was developed by InControl Simulation Solutions. This application is a platform for carrying out simulation of a Business process. Models in this application are built by a drag- anddrop method. This software does not necessarily make use of any of the notations discussed, but it supports the model of Business Process through workflow technique. The main function of this software is to carry out simulation of a serial model. Though it is mainly used in the manufacturing sector, it can also be useful in other aspects of Industries. In the Enterprise Dynamics, the activities and roles are represented as servers. When simulated, the efficiency of the server (in $\%$ ) is shown. Representing how the performance of each activity. A graph and simulation report is generated to carry out analysis.

This software makes use of a petri net - like and workflow technique in the representation of processes carried out, the blue circles represents the nodes in this process, moving from one server to another as the Business Process takes place.

This software is best suitable if a modeller is just concerned about the serial flow of activities and not concerned about the roles in carrying out the activities. Depending on the number of employees in carrying out tasks, the modelling of a process using this software can be very complex.

6. Accuprocess Modeller: The Accuprocess software is developed as an Easy-to- Use application compared to most other process modelling software. Accuprocess makes use of only one notation, BPMN 1.0 (similar to the flow 
chart) which has few notations in carrying out a modelling exercise. This software provides free documents and trainings in which a new user can quickly learn how to use the software.

7. ARIS Toolset: ARIS toolset is made up of different products developed by IDS Scheer, a company established by Prof. August-Wilhem Scheer, whose academic research brought about Architecture of Integrated Information Research (ARIS). IDS Scheer was developed to in 1984 to market the ARIS reference framework, but the company was later acquired by Software AG in 2010. The ARIS product was first released in 2009. Business Process Modelling on ARIS products is based on BPMN2.0 and EPC.

To further explain the techniques and tools of Business Process Modelling based on the comparative analysis, the modelling and simulation process in this subsection is carried out using software which makes use of a technique easily communicated and with simulation capability. Compared to other Business Process Software, Accuprocess Modeller provides full functionality (modelling \& simulation) in its trial version

\subsection{Case Study: Simulation Scenario}

In this case scenario, only the activities directly involved with the receipt of goods of an organization are modelled. Ten actions are carried out with two decision points to determine the path to take. The scenario is outlined in table 3 . In the decision points, probability of getting a defective batch is $20 \%$, good batch $80 \%$; second decision point, probability of being damaged after being received (due to poor handling) is $10 \%$, and being the fault of the supplier, $90 \%$. The average time for the longest activity is 20 minutes, while the least activity takes 2 minutes. This process runs 600 times (i.e. 600 batches of goods are received).

Accuprocess Modeller. The Accuprocessor modeller is divided into two aspects; modeller and Simulation. In the modeller section, all the necessary notations to model the system are provided in a canvas. The modelling of the system is done by a drag-and-drop method.

A drag-and-drop canvas is provided, selecting the different objects to use in mapping the Business Process. Figure 2 depicts the process model of the Incoming goods received in the company. In the Accuprocess, the simulation is further sub-divided into two areas; the resource area, where the Organizational unit in which the roles can be assigned to are situated - and the scenario- in which the simulation is to be carried out. Each activity is assigned to a role which is in the simulation resources. The vital activities to be part of the simulation exercise are included in the scenario, the execution time of each of these activities are further specified. Accuprocess gives the modeller option to specify the type of distribution, for purpose of the simulation carried out, a normal distribution is used.

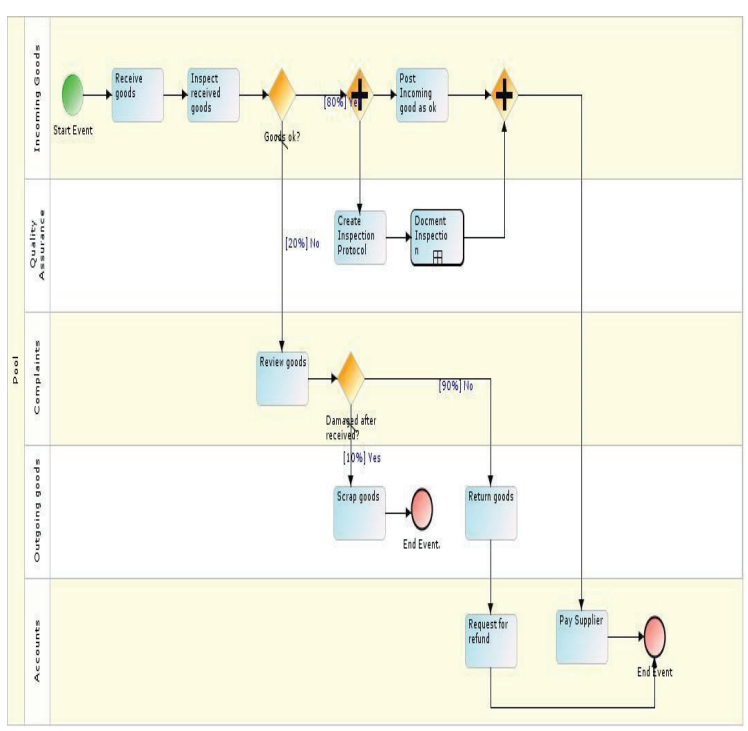

Figure 2: Incoming Goods process model in the relevant running scenario.

After the AS-IS configuration has been completed, a simulation is run to determine the state of operations in the Organization. A brief simulation run summary is displayed on the application interface. To view a detailed report to carry out analysis, an html file is generated displaying all the parameters and configurations. The complete steps in modelling and the simulation of the Business Process using the Accuprocess Modeller are included in the supporting document of this report. Figure 3 shows a brief summary of the simulation report.

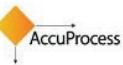

Simulation Summary Report

\begin{tabular}{ll}
\hline Scenario Name & Cost \\
Description & amount \\
ProcessFlow Name & Incoming goods \\
Resources Name & Goods_reciepts \\
Comments & Fri Sep 05 12:31:00 BST 2014 \\
Start Time & Sun Sep 07 14:27:37 BST 2014 \\
End Time & $£ 5,225.69$ \\
Total Cost & 49.94 Hours \\
Total Time Taken & 600 \\
No. of Runs Completed & \\
\hline
\end{tabular}

Figure 3: Simulation Summary report. 
Table 2: Business Process Modelling Software comparative characteristics evaluation.

\begin{tabular}{|c|c|c|c|c|c|}
\hline & $\begin{array}{c}\text { Notation/ } \\
\text { Techniques }\end{array}$ & Functionality & $\begin{array}{c}\text { Operating } \\
\text { System }\end{array}$ & $\begin{array}{c}\text { Application } \\
\text { Mode }\end{array}$ & $\begin{array}{c}\text { Documentation } \\
\text { Format }\end{array}$ \\
\hline $\begin{array}{l}\text { Adonis } \\
\text { (Community } \\
\text { Ed.) }\end{array}$ & BPMN 2.0 & $\begin{array}{l}\text { Model } \\
\text { Design, } \\
\text { Simulation }\end{array}$ & Windows & Stand-alone & Pdf, html \\
\hline $\begin{array}{l}\text { Enterprise } \\
\text { Architect } \\
\text { 11.1 Suite } \\
\text { (Ultimate) }\end{array}$ & $\begin{array}{l}\text { UML, } \\
\text { SysML, } \\
\text { BPMN 2.0, } \\
\text { BPEL }\end{array}$ & $\begin{array}{c}\text { Model } \\
\text { Design, } \\
\text { Simulation, } \\
\text { Code } \\
\text { Execution }\end{array}$ & $\begin{array}{c}\text { Windows, } \\
\text { Linux, Mac }\end{array}$ & $\begin{array}{l}\text { Web, Stand- } \\
\text { alone }\end{array}$ & $\underset{\mathrm{rtf}}{\text { Pdf, html, docx, }}$ \\
\hline $\begin{array}{l}\text { Microsoft } \\
\text { Visio 2013 } \\
\text { (Professional) }\end{array}$ & $\begin{array}{l}\text { BPMN 2.0, } \\
\text { UML, IDEF0, } \\
\text { Flowchart }\end{array}$ & $\begin{array}{c}\text { Model } \\
\text { Design, } \\
\text { Simulation }\end{array}$ & Windows & $\begin{array}{l}\text { Web, Stand- } \\
\text { alone }\end{array}$ & vsdx, vsdm \\
\hline $\begin{array}{l}\text { Bizagi BPM } \\
\text { Suite }\end{array}$ & BPMN 2.0 & $\begin{array}{l}\text { Model } \\
\text { Design, } \\
\text { Simulation, } \\
\text { Code } \\
\text { Execution. }\end{array}$ & Windows & Web & docx, xlsx \\
\hline \begin{tabular}{|l} 
Enterprise \\
Dynamics
\end{tabular} & $\begin{array}{l}\text { Workflow, } \\
\text { Petri net }\end{array}$ & Simulation & Windows & Stand-alone & Mod, bmp \\
\hline $\begin{array}{l}\text { ARIS } \\
\text { Express }\end{array}$ & $\begin{array}{l}\text { BPMN 2.0, } \\
\text { EPC }\end{array}$ & Model Design & $\begin{array}{c}\text { Windows, } \\
\text { Linux, Mac }\end{array}$ & Stand- alone & Adf, pdf, rdf \\
\hline $\begin{array}{l}\text { ARIS } \\
\text { Business } \\
\text { Simulator }\end{array}$ & $\begin{array}{l}\text { BPMN 2.0, } \\
\text { EPC }\end{array}$ & $\begin{array}{c}\text { Model } \\
\text { Design, } \\
\text { Simulation }\end{array}$ & $\begin{array}{r}\text { Windows, } \\
\text { Linux, Mac }\end{array}$ & $\begin{array}{c}\text { Stand-alone, } \\
\text { web }\end{array}$ & Adf, pdf, rdf \\
\hline $\begin{array}{l}\text { Accuprocess } \\
\text { (Professional } \\
\text { Ed.) }\end{array}$ & BPMN 1.0 & $\begin{array}{l}\text { Model } \\
\text { Design, } \\
\text { Simulation }\end{array}$ & $\begin{array}{c}\text { Windows, } \\
\text { Mac }\end{array}$ & Stand-Alone & $\begin{array}{l}\text { Pm, Html, pdf, } \\
\text { docx, jpg }\end{array}$ \\
\hline
\end{tabular}

Table 3: AS-IS Employee Configuration for the running scenario.

\begin{tabular}{|c|c|c|c|c|}
\hline $\begin{array}{c}\text { Organizational } \\
\text { Units }\end{array}$ & $\begin{array}{l}\text { Number of } \\
\text { Employees }\end{array}$ & $\begin{array}{c}\text { Cost per } \\
\text { Employee } ₹ \\
\text { (Hourly) }\end{array}$ & $\begin{array}{c}\text { Activities Carried } \\
\text { out }\end{array}$ & $\begin{array}{c}\text { Duration Per } \\
\text { Activity (minutes) }\end{array}$ \\
\hline \multirow[t]{3}{*}{$\begin{array}{l}\text { Incoming } \\
\text { Goods }\end{array}$} & \multirow[t]{3}{*}{10} & \multirow[t]{3}{*}{10} & Receive goods & 10 \\
\hline & & & Inspect goods & 20 \\
\hline & & & Post goods as ok & 2 \\
\hline \multirow[t]{2}{*}{$\begin{array}{l}\text { Quality } \\
\text { Assurance }\end{array}$} & \multirow[t]{2}{*}{4} & \multirow[t]{2}{*}{15} & $\begin{array}{l}\text { Create Inspection } \\
\text { Protocol }\end{array}$ & 10 \\
\hline & & & Document protocol & excluded \\
\hline Complaints & 4 & 9 & $\begin{array}{l}\text { Review defective } \\
\text { goods }\end{array}$ & 20 \\
\hline \multirow[t]{2}{*}{$\begin{array}{c}\text { Outgoing Goods } \\
\text { Department }\end{array}$} & \multirow[t]{2}{*}{5} & \multirow[t]{2}{*}{10} & Scrap goods & 5 \\
\hline & & & Return goods & 5 \\
\hline \multirow[t]{2}{*}{ Accounting } & \multirow[t]{2}{*}{2} & \multirow[t]{2}{*}{25} & Refund Request & 2 \\
\hline & & & Pay Supplier & 2 \\
\hline
\end{tabular}

Graphs generated from the simulation run are shown in figure 4 depicting the result of the simulation carried out after 600 runs. The first graph shows the average utilization of the different units of the process in percentage, with Incoming Goods unit being more utilized. The run time graph depicts the maximum, minimum, and average time taken for one run to be completed in hours. The full summary report of the simulation can be viewed in the supporting documents attached to this report.
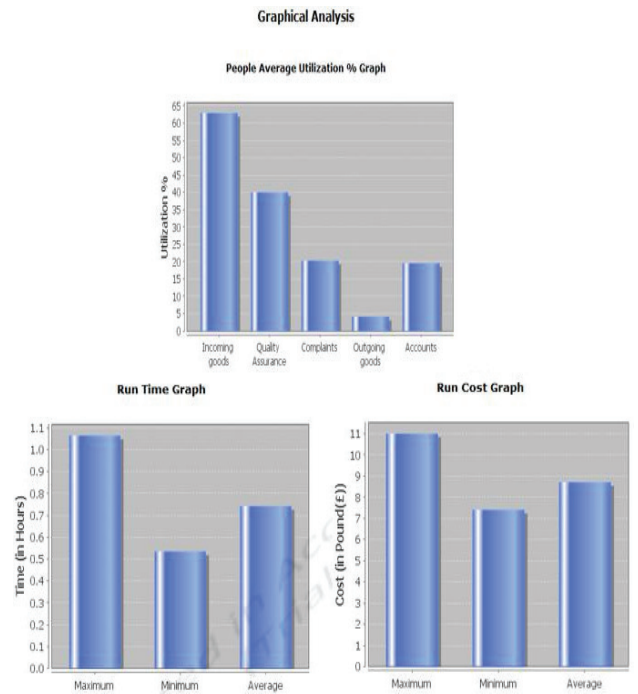

Figure 4: Graphical Analysis of the Model.

\section{Advantages of Accuprocess Modeller.}

- Easy to learn, and communicate the designed model

- The report generated is easily understandable

- Documentation of the model is achieved using a format *.jpg (for images), .docx (Microsoft word), html and pdf which is accessible in multiple platforms.

- It's a stand-alone app; the models are easily designed without connecting to the internet. The designs are not stored in a database not operated by the Organization.

- It's a light application easily downloaded and installed. Does not make use of an external database in its operations.

- Suitable for small and medium scale business

Disadvantages. In using the Accuprocess, only the hierarchical flow of activities can be modelled, not possible to model the structural hierarchy. This is due to the setback in using the BPMN, which is the only technique this software uses. Some software such as ARIS products, and Microsoft Visio, gives the modeller the Organization Chart option in the design. 
In using a lesser suite or package, modelling and analysis is only carried out. But in carrying out the optimization of operations, physical observations have to be carried out, or by manually testing different values. In using the Enterprise edition, the optimization is automatically carried out by the software, saving the time and expenses carrying out the observations or changes would have cost. The disadvantages stated here is not restricted to Accuprocess Professional Edition, but some other less expensive Business Process Software.

ARIS Business Simulator. A similar process is being modelled and simulated using ARIS Business Simulator. This is done to show the ability to optimize process automatically. The optimization aim is to determine the least number of employees to carry out each run of the process at a faster time with less cost. It should be noted that the simulation exercise using the ARIS Business Simulator was not carried by the author. It was obtained from the ARIS forum to carry out the comparison. Therefore some parameters and configurations will have some slight changes, but still similar approaches.

Based on the configuration of the process, the cost and time in operations vary. During the process analysis, the effect of different process configuration and resources are checked in a simulation environment. These configurations are automatically created by the simulator. The results obtained are saved to be compared and evaluated for the optimization of the process.

The type of Business Process Model technique is specified, in this case EPC is used; the database to use is selected; and the model in which to carry out the simulation is defined. In carrying out the experiment, the attribute of the objects are varied, the highest and lowest limits of the objects (in this case, all the Organizational Units) are specified; the low and high text field. This is referred to as Factor Variation.

Depending on the configuration in the Factor Variation, many scenarios are created.

Table 4: TO-BE Employee Optimization Configuration.

\begin{tabular}{|l|l|l|}
\hline \multicolumn{1}{|c|}{ Organizational Units } & Minimum Staff & Maximum Staff \\
\hline Incoming Goods Department & 1 & 15 \\
\hline Accounting & 1 & 10 \\
\hline Quality Assurance & 1 & 10 \\
\hline Complaints Department & 1 & 10 \\
\hline Outgoing Goods Department & 1 & 10 \\
\hline
\end{tabular}

The next step is to specify the responses to be saved, in this case scenario, the throughput time for the model (Receipt of Goods), and the idle time cost for the objects (the Organizational units).

In carrying out the simulation, the optimization configuration has to be specified according to what is to be achieved. In this case, minimization of the model and objects is specified.

In the ARIS software, one of the documentation format used is Microsoft Excel; this makes the analysis to be carried out easier. After all parameters has been set in the simulation the output formatExcel- is specified, and a file is created for the result to be viewed and saved.

The generated output Microsoft Excel file of the simulation is displayed, showing the values for the different objects, the factors, and responses based on the amount of possible configuration being run.

The optimization configuration is compared from the values in the objective column which is generated automatically. These values are further compared to idle time cost of the different responses. This process can be made easier by sorting the values according to ascending or descending order, or by generating a graph based on the values.

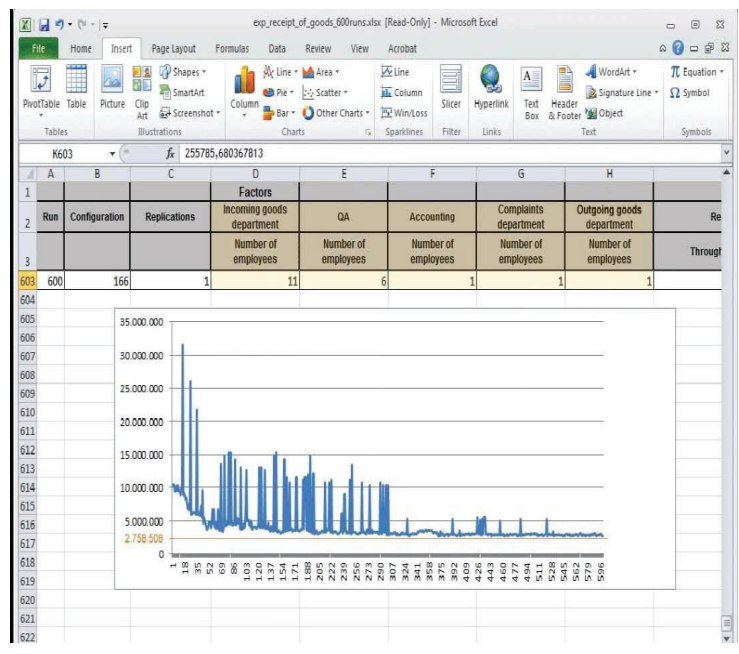

Figure 5: ARIS software provided Optimization graph.

The lowest objective value which is the idle time cost provides the result for the factors. From figure 5 above the result was gotten in the configuration run 166 with the factors values as;

Table 5: Required numbers of employees.

\begin{tabular}{|l|l|}
\hline \multicolumn{1}{|c|}{ Organizational Unit } & Employees Required \\
\hline Incoming Goods Department & 11 \\
\hline Quality Assurance & 6 \\
\hline Accounts & 1 \\
\hline Complaints Department & 1 \\
\hline Outgoing Goods Department & 1 \\
\hline
\end{tabular}


Table 5 shows the required staff of the different units needed to receive goods at the lowest possible throughput time at the least idle time cost.

Advantages.

- Suitable for the large scale businesses, and for modelling the Enterprise

- Used in illustrating the structural hierarchy of the enterprise

- Gives the user ability to automatically optimize the process

\section{Disadvantage.}

- A major disadvantage in using the EPC which is the major techniques used in this software is the specification of roles for every function/carried carried out by adding the Organization unit notation. Using this makes the model quite messy compared to the arranged format in using the BPMN.

\section{DISCUSSION - CONCLUSIONS}

Business Process Model as a topic aims at improving the operations of an Organization. However, the presence of numerous techniques and tools has created a setback to modelling a Business Process. In this study, a comparison have been carried out to enable a potential user understand the usability of these techniques and tools.

The techniques were compared using features necessary for having a complete Business Process Model; data flow, logical reasoning, specification of roles, and capability of simulation. A technique possessing all the features will be effective for use in these four target areas of an Organization:

- Production Planning: Goods/services to be produced - the conversion of the input into output.

- Organizational Structure: With the structural view, the management determines the relationship between the tasks and equipment/personnel/units; useful for the Human resource unit of an Organization.

- Logistics: The flow of products; not only how it's being produced in the Organization, but also to the point of consumption, how the requirements are met.

- Strategic Planning: The strategic planning involves a futuristic plan for the Organization. Using the techniques and tools, the AS-IS model is analysed, improved upon to generate the TO$\mathrm{BE}$ model. Simulation is carried out to determine the result of the future plan. This is done to reduce cost of actually implementing a plan that might be a failure.

Though techniques such as EPC, IDEF, WORKFLOW, and BPMN all have the features mentioned, it is necessary for a modeller to consider one which is easily understandable to stakeholders; easy in the communication of processes involved in the business, and to also facilitate learning. From the study, the EPC and the BPMN technique clearly states the activities, roles, the flow of messages (in BPMN), documents to be read, and requirements for a task to be carried out. These two techniques also give a clear outline of the structure of an Organization.

Some major software tools were analysed in this study to determine what requirements to look out for in choosing Business Process software. The comparison showed that most software packages make use of BPMN technique in the modelling of a Business Process. Judging from the outcome of this study, it is best to choose a software tool which not only models a system, but, also, it is able to carry out its simulation. It was shown that some software tools with the simulation functionality do provide only analysis of the AS-IS model, while others go further to enable optimization of the Business Process to be carried out producing the TO-BE Business Process Model.

This study ended with simple simulation scenarios carried out to show the importance of modelling and simulating a Business Process to improve the operations of an Organization.

Undoubtedly, Business Process Modelling is relevant in improving a system, and researches carried out in relation to this topic are still very active. Nevertheless, some important areas in relation to this topic are yet to be covered, as:

- BPM techniques are most times mixed with other modelling techniques such as Software and Data Modelling, though some techniques are applicable to different process model. This makes it difficult to distinguish which is most suitable for Business Process.

- Standardization of Business Process Model software due to the presence of numerous tools.

- With the popularity of Lean Six Sigma, a future research on the Integration of Business Process Management and Lean Six Sigma is to be carried out to further strengthen the techniques used in carrying out continuous improvement of an Organization. 


\section{REFERENCES}

Aguilar-Saven, R. S. (2003). Business Process Modelling: Review and Framework. International Journal of Production Economics (90), 129-149.

Badica, C., Badica, A., \& Litoiu, V. (2003). Role Activity Diagrams as Fininte State Process. Second International Symposium on Parrellel and Distributed Computing (pp. 15-22). IEEE.

Bridgeland, D. M., \& Zahavi, R. (2009). Business Modelling - A Practical Guide to Realizing Business Value. Burlington: Morgan Kaufmann.

Business Process Modelling. (2007). Retrieved 06 21, 2014, from Business Process Modelling: http://www.businessprocessmodelling.co.uk

Business Process Modelling. (2013). Retrieved June 24, 2014, from BusinessBalls.com: http://www.business balls.com/business-process-modelling.htm

Kalnins, A., Kalnina, D., \& Kalis, A. (n.d.). Comparison of Tools and Languages for Business Process Reengineering. http://citeseerx.ist.psu.edu/viewdoc/ download?doi=10.1.1.127.1036\&rep=rep1\&type=pdf

Prezel, V., Gašević, D., \& Milanović, M. (n.d.). Representational Analysis of Business Process and Business Rule Languages. Retrieved 06 04, 2014, from OntoRule Project: http://ontorule- project.eu/ attachments/075_buro2010_paper_2.pdf

Recker, J., Indulska, M., Rosemann, M., \& Green, P. (2009). Business Process Modelling - A Comparitative Analysis. Journal of the Association for Information System, 10 (4), 333-363.

Vergidis, K., Tiwari, A., \& Majeed, B. (2008). Business Process Analysis and Optimization: Beyond Reengineering. IEEE Transactions on systems, man, and cybernetics - part c: applications and reviews, 6982.

Yamamoto, R., Yamamoto, K., Ohashi, K., \& Inomata, J. (2005). Development of a Business Process Modeling Methodology and a Tool for sharing Business Processes. 12th Asia-Pacific Software Engineering Conference (APSEC'05), IEEE. 